\title{
Colonización y los cuerpos-territorio: protagonismo de las mujeres indígenas en el conflicto por el TIPNIS, Bolivia
}

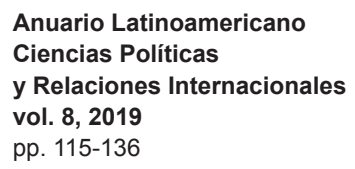

DOI: $10.17951 /$ al.2019.8.115-136

\section{Colonization and the Bodies-Territory. Leadership of Indigenous Women in the TIPNIS Conflict, Bolivia}

\author{
Gaya Makaran* \\ CENTRO DE INVESTIGACIONES SOBRE AMÉRICA LATINA Y EL CARIBE \\ UNIVERSIDAD NACIONAL AUTÓNOMA DE MÉXICO \\ $\triangle$ gmakaran@unam.mx \\ https://orcid.org/0000-0002-6343-0003
}

\section{RESUMEN}

El presente artículo tiene como objetivo mostrar el papel de las mujeres indígenas en la defensa del Territorio Indígena y Parque Nacional Isiboro Secure (TIPNIS) en la Amazonía boliviana, frente al proyecto carretero y la colonización cocalera promovidas por el gobierno de Evo Morales Ayma. El estudio de la resistencia en el TIPNIS nos servirá para ilustrar la relación actual entre el colonialismo, el capitalismo y el patriarcado, por una parte, y la (auto)identificación de los cuerpos femeninos con el territorio en disputa. Estamos partiendo de un contexto global y nacional más amplio, donde el Estado boliviano bajo los gobiernos "progresistas" del Movimiento al Socialismo (MAS) se caracteriza por un nacionalismo unificador y "modernizante" basado en el extractivismo acelerado y una proyección desarrollista que contradice los principios plurinacionales y proindígenas declarados, y asevera el despojo de los territorios y recursos por el capital, sobre todo transnacional.

PALABRAS CLAVE: colonización, patriarcado, cuerpos-territorio, mujeres indígenas, TIPNIS.

\section{ABSTRACT}

This article aims to show the role of indigenous women in defending the Indigenous Territory and National Park Isiboro Secure (TIPNIS) in the Bolivian Amazonia versus the highway project and the cocalero colonization promoted by the government

* Doctora en Humanidades y Ciencias de Literatura por la Universidad de Varsovia. Investigadora Titular A de la Universidad Nacional Autónoma de México (UNAM). Investigadora del Centro de Investigaciones sobre América Latina y el Caribe (CIALC) de la UNAM. Se especializa en nacionalismos y cuestiones étnicas en Bolivia y Paraguay contemporáneos. 
Dossier América Latina: género y política of Evo Morales Ayma. The study of resistance in the TIPNIS will serve to illustrate the current relationship between colonialism, capitalism and patriarchy, on the one hand, and the (self) identification offemale bodies with the territory, on the other. We start from a broader global and national context where the Bolivian state, under the "progressive" governments of the Movimiento al Socialismo (MAS), is characterized by a unifying and "modernizing" nationalism based on accelerated extractivism and a developmentalist projection that contradicts the avowed plurinational and proindigenous principles, and asserts the dispossession of territories and resources by transnational capital.

KEYWORDS: colonization, patriarchy, bodies-territory, indigenous women, TIPNIS.

\section{Introducción}

Si nos acercamos a la larga y sinuosa historia de conquista y colonización de las tierras y poblaciones de América - Abya Yala veremos que, a pesar de los cambios en el discurso legitimador que las acompañaba, éstas han sido vinculadas con la acumulación del capital, seguida por el proyecto de homogeneización cultural que tenía como objetivo asegurar la hegemonía plena de la empresa colonizadora.

Ocupar el vacío, sembrar el progreso, hacer trabajar la tierra y a los humanos hasta entonces "improductivos e inútiles", ambiciones que los Estados compartían con el capital privado y que se llevaban a cabo sin conmiseración alguna para el colonizado; someter y combatir lo otro y al otro como incompatible con el propósito de un monopolio epistémico planetario del capitalismo; quemar la selva "salvaje" con el fuego de la civilización, puesto que la Tierra no es madre, sino una virgen que hay que poseer, penetrar y domar violentamente; estas son pautas del ethos colonizador que ha pervivido hasta nuestros días.

En este sentido, los cuerpos humanos, y en particular los cuerpos femeninos y/o feminizados, se convierten en el objeto necesario de la conquista, sumisión, destrucción o transformación forzada. Los cuerpos violentados, reducidos y condenados a la explotación reflejan de manera simbólica la misma suerte de los territorios colonizados: trazados y renombrados, cortados con alambres de propiedad y de frontera, explotados y finalmente destruidos en nombre del progreso y la civilización.

La colonización actual que padecen los territorios y sus habitantes indígenas en América Latina, aunque pudo haber cambiado de apariencias frecuentemente disimulada por "sutiles fuerzas disolventes" del mercado (Díaz Polanco, 2006), de ninguna manera dejó atrás la violencia y el despojo directos. Es necesariamente multidimensional: física o simbólica, política, económica, sociocultural, identitaria, etc. Se lleva contra los modos diversos de pensar el mundo y de reproducir la vida, que son destruidos o subordinados a las lógicas "modernas" que viabilizan la acumulación del capital. Así, la reproducción 
de la vida es subordinada a la reproducción del capitalismo que, como decía Marx, necesita de una "colonización sistemática" consistente en la expropiación del ser humano de su capacidad de autonomía, al quitarle los medios necesarios (originalmente la tierra) y obligarlo a subsumirse al trabajo enajenado, donde las necesidades básicas se satisfacen en el mercado.

Esto conduce a la ampliación del dominio del capital y de la monocultura "occidental" europeizante, donde una de las características más importantes es el carácter patriarcal de relaciones sociales. De hecho, la colonización capitalista desde sus inicios está profundamente permeada por los valores patriarcales, al ser la mujer el objeto de conquista y despojo multidimensional, igual que la tierra y sus recursos tomados y explotados violentamente. Para ilustrar este vínculo inseparable entre el colonialismo, capitalismo y patriarcado, encarnado en el ethos colonizador, citemos el poema Los conquistadores de la selva de Raúl Otero Reiche (1906-1976), oriundo de Santa Cruz de la Sierra, la capital del Oriente boliviano:

La selva es una virgen que no se entrega

Nunca, tendremos que arrancarle por

Fuerza la palabra, vestirla de ciudades.

Ceñirle con caminos los muslos

Quemar su piel velluda con sangre

De progreso y civilizaciones. (Citado en Parejas Moreno, 2008, p. 11)

Esta personificación de la selva en una virgen indomable que tiene que ser amansada por fuerza por el macho conquistador valiente y aventurero convertido en el misionero violento del progreso y civilización nos ayuda a entender el carácter real de la empresa civilizadora, donde las poblaciones indígenas han sido forzadas a integrarse o desaparecer y marcadas "con la sangre de progreso y civilización".

Este despojo de las capacidades de autonomía personal y social de las mujeres, destrucción de sus sabidurías, vínculos de solidaridad y la libertad en cuanto a sus cuerpos y vidas, paralelo a la dominación violenta de la tierra, la naturaleza y sus recursos, está estrechamente vinculado con el nacimiento y el desarrollo del capitalismo y del Estado moderno, como lo describe magistralmente Silvia Federici en su ya clásico libro Calibán y la bruja (Federici, 2010). En América Latina, este proceso no se ha realizado plenamente, al quedar territorios, si no libres, por lo menos no totalmente penetrados por las lógicas "modernas", donde las mujeres indígenas se vuelven defensoras más decididas de los territorios y los modos de vida comunitarios. Sus cuerpos se convierten simbólicamente en el territorio mismo, puesto que, igual que éste, son dadoras y sustentadoras de la vida y, al mismo tiempo, objetos de conquista y colonización por parte del mundo "desarrollado": "Los territorios indígenas son resignificados como femeninos, los cuerpos de las mujeres indígenas son resignificados como territorio. En esta última ronda de desposesión de tierras
Colonización y los cuerpos-territorio: protagonismo de las mujeres indígenas en el conflicto por el TIPNIS, Bolivia

Gaya Makaran 
Dossier América Latina: género y política indígenas, los cuerpos femeninos una vez más son representados como abiertos, vulnerables, disponibles, desechables y como símbolo de honor" (Belausteguigoitia y Saldaña-Portillo, 2015, p. 34).

La asociación de la mujer con la naturaleza, el territorio y la Madre Tierra, destacada por la corriente del ecofeminismo ${ }^{1}$, las lleva a las mujeres indígenas a "intervenir públicamente para corregir los desequilibrios en la gestión de los recursos naturales que perjudican a las mujeres y que contribuyen a la degradación del medioambiente", como asegura Vandana Shiva (Shiva, 1995, p. 22). La retomamos, más allá de sus enfoques esencialistas y deterministas, de la autodefinición de las mismas mujeres indígenas, visible en sus testimonios, donde destacan su papel de reproductoras y cuidadoras de la vida en común. De ninguna manera se trata de naturalizar el papel de la mujer, ni exaltar sus presuntos rasgos biológicos y espirituales innatos que la vinculen de manera especial con la naturaleza, lo que nos interesa es más bien destacar el rol social históricamente construido de las mujeres indígenas en sus comunidades que las acerca a labores de la reproducción de la vida material y simbólica, dirigidas a la alimentación, la medicina y la educación, directamente vinculadas con la existencia de los espacios y los bienes naturales que las hacen posibles. Eso significa que la destrucción del territorio las afecta directamente a ellas, dificultando, o incluso imposibilitando, el cumplimiento de su rol social, al ser las mujeres y sus hijos/as los más perjudicados por la pauperización derivada del proyecto "modernizador" del despojo territorial y saqueo de bienes comunes.

A eso hay que añadir la violencia física que se desata contra sus cuerpos, donde no sólo es el Estado y el capital que las reprimen, sino no pocas veces resultan ser sus propios compañeros el mayor obstáculo para la lucha común. Así, el patriarcado permea las relaciones sociales dentro de las comunidades para debilitarlas, no pocas veces convirtiéndose los varones indígenas, paradójicamente, en sujetos contrainsurgentes y disciplinadores de las resistencias femeninas, eso debido tanto a su visión machista de las relaciones de género, como a su subsunción al mercado laboral (salario) y al clientelismo político (prebendas, ascensos, etc.). Frente a esta opresión interna, las mujeres indígenas reivindican la importancia de su papel de cuidadoras y reproductoras de la vida que hace posible la perpetuación biológica y cultural de sus pueblos. En este sentido, en las últimas décadas observamos una politización de los trabajos de cuidado y reproducción, donde las mujeres ganan un nuevo protagonismo en las organizaciones indígenas, tradicionalmente dominadas por los hombres, empoderándose de los espacios tradicionales de negociación varonil con el Estado-capital y transformándolos con su beligerancia contra proyectos de alto impacto socioambiental.

1 Véanse los acercamientos de: Shiva, 1995; Shiva y Mies, 1997; Gargallo Celentani, 2014; Gómez Grijalva, 2013; Millán, 2014; Belausteguigoitia Ruis y Saldaña-Portillo, 2014; Santa Cruz, 2008. 
El presente artículo tiene como objetivo mostrar el papel de las mujeres indígenas en la defensa del Territorio Indígena y Parque Nacional Isiboro Secure (TIPNIS) en la Amazonía boliviana, frente al proyecto carretero y la colonización cocalera promovidas por el gobierno de Evo Morales Ayma. El estudio de la resistencia en el TIPNIS nos servirá para ilustrar la relación actual entre el colonialismo, el capitalismo y el patriarcado, por una parte, y la (auto) identificación de los cuerpos femeninos con el territorio en disputa, por otra. Estamos partiendo de un contexto global y nacional más amplio, donde el Estado boliviano bajo los gobiernos "progresistas" del Movimiento al Socialismo (MAS) se caracteriza por un nacionalismo unificador y "modernizante" basado en el extractivismo acelerado y una proyección desarrollista que contradice los principios plurinacionales y proindígenas declarados, y asevera el despojo de los territorios y recursos por el capital, sobre todo transnacional.

Nos basaremos en el análisis del material de la investigación de campo llevada en la Amazonía boliviana, especialmente en los testimonios recogidos durante el encuentro de organizaciones y autoridades indígenas en el Cabildo Indigenal y en la Subcentral del TIPNIS en la ciudad de Trinidad (Beni) en abril de $2017^{2}$. Los resultados completos de dicha investigación fueron originalmente publicados en el libro de coautoría Recolonización en Bolivia. Neonacionalismo extractivista y resistencia comunitaria (Makaran y López, 2018), al ser el presente artículo una reinterpretación acotada de los hallazgos previos, enriquecida por los aportes del ecofeminismo y feminismos comunitarios.

\section{La colonización y la resistencia en el TIPNIS en los gobiernos del MAS}

La historia de ocupación y colonización de la Amazonía boliviana y su vinculación con la economía mundial y sus ciclos de acumulación nos permite entender el carácter de las relaciones que se establecieron entre la población indígena y los poderes tanto locales como nacionales, marcadas por el ethos colonizador que ha sobrevivido hasta nuestros días. Si nos fijamos ya en el periodo republicano de Bolivia, la selva se concibió como un territorio baldío que sólo cobraba sentido en cuanto pudiera ser subsumido a la lógica del capital, ya sea como fuente de recursos ya fuera como territorio de paso de las mercancías, y sus habitantes, según esta visión, simplemente sobraban como improductivos y entorpecedores del progreso. Así en los siglos XIX y XX, la barraca cauchera con su régimen de esclavitud de la población nativa se convierte para el Estado boliviano en el enclave de la modernidad y del pro-

2 Se trata de las Jornadas de Trabajo sobre las Acciones de Defensa por el TIPNIS convocadas por la CIDOB orgánica, donde participaron: Subcentral del TIPNIS, Subcentral de Mujeres del TIPNIS, Confederación de Mujeres Indígenas de Bolivia (CNAMIB), Coordinadora Andina de Organizaciones Indígenas (CAOI), Central de Pueblos Étnicos Mojeños del BENI (CPEMB).
Colonización y los cuerpos-territorio: protagonismo de las mujeres indígenas en el conflicto por el TIPNIS, Bolivia

Gaya Makaran 
Dossier América Latina: género y política greso capitalista. Los indígenas selváticos eran vistos como parte de la naturaleza salvaje que obstaculizaba la marcha modernizadora y ralentizaba los tiempos del capital. Si no podían ser usados como mano de obra esclava, se "borraban" como cualquier otro obstáculo natural.

Estas relaciones históricas entre el Estado, el capital y las poblaciones indígenas de la Amazonía boliviana, que por cuestiones de espacio hemos optado por reducir a una simple mención, han marcado fuertemente el imaginario de los gobernantes del país con un sello colonial imborrable, y actualmente se renuevan en el gobierno de Evo Morales en una severa contradicción con sus premisas plurinacionales y el discurso supuestamente proindígena. En los siguientes apartados presentaremos la historia y la actualidad del conflicto por el TIPNIS, las dimensiones de la colonización promovida por el gobierno del MAS y la resistencia de los habitantes indígenas del territorio, con el papel destacado de las mujeres.

\section{Proyecto carretero y la VIII Marcha por el TIPNIS}

En el año 2007, el gobierno del MAS a la cabeza de Evo Morales presenta el proyecto para la construcción de una carretera que uniría dos localidades en el centro del territorio boliviano: Villa Tunari en el Chapare (Cochabamba) con San Ignacio de Moxos en el suroeste del Beni, como parte del llamado "Corredor Norte" en la macrorregión amazónica, cuyo objetivo sería la integración vial del país y su inserción a las dinámicas continentales. Según el proyecto, la carretera atravesaría el Territorio Indígena Parque Nacional Isiboro Sécure (TIPNIS $)^{3}$, pasando por su núcleo intangible, constituyendo una grave amenaza, tanto en el sentido ecológico, como social. En agosto de 2008, la entonces Administradora Boliviana de Carreteras (ABC) suscribió el documento de adjudicación de la obra a favor de la empresa brasileña constructora de carreteras OAS. Será en el mes de abril del 2011 que la Asamblea Legislativa Plurinacional (ALP) aprueba el crédito otorgado por del Banco Nacional de Desenvolvimiento Económico y Social (BNDES) de Brasil para la construcción de la carretera, lo que se traducirá en el ingreso de la maquinaria pesada

3 El TIPNIS, un área aproximadamente de 1.200.000 hectáreas, está situado entre los departamentos de Beni y Cochabamba y se encuentra bajo la jurisdicción de los municipios de San Ignacio de Moxos y Loreto, en Beni y Villa Tunari en Cochabamba. Ha sido habitado originalmente por tres pueblos indígenas: mojeño-trinitario, yuracaré y t’simán que son básicamente cazadores, recolectores, pescadores y, de manera itinerante, agricultores. De acuerdo con el Censo Nacional de 2001, la población indígena del TIPNIS era de 4.106 habitantes, distribuidos en 64 comunidades. El TIPNIS es un Parque Nacional y un Territorio Indígena, esto significa que posee una doble condición: la de ser "área protegida” y a la vez "territorio indígena”, condición que le fue oficialmente reconocida en 1990 (Decreto Supremo 22610) como resultado de la I Marcha Indígena por el Territorio y la Dignidad coordinada por las organizaciones indígenas de las tierras bajas (Véase Makaran y López, 2018). 
a las entradas del Parque. Cabe destacar que en ningún momento de este proceso se cumplió con el derecho indígena a la consulta previa, libre e informada, prevista en caso de cualquier actividad que afecte sus territorios.

Así, del 15 de agosto al 19 de octubre de 2011 se realiza la VIII Gran Marcha Indígena por la Defensa del TIPNIS (que aquí llamaremos la VIII Marcha). Estos 65 días, marcados por descalificaciones y represión directa de parte del gobierno y sus aliados, cuya expresión más violenta tendrá lugar el día 25 de septiembre en Chaparina, finalizan con la llegada de los marchistas a la ciudad de La Paz, donde miles de ciudadanos los recibirán y se sumarán a la movilización. La posición intransigente y represiva del gobierno del MAS provocará la indignación de los movilizados y desencadenará la ruptura de las organizaciones indígenas con el gobierno. Finalmente, ante la presión de los movilizados el gobierno se verá obligado a interrumpir el proyecto carretero y a promulgar la Ley 180 que declara "intangible" al TIPNIS y prohíbe expresamente la ruta y otros proyectos de alto impacto socioambiental. De esa manera, el plan gubernamental de construcción de una carretera por el corazón del TIPNIS fue aparentemente frenado por la movilización indígena y ciudadana, lo que muchos tomaron en aquel momento como un triunfo y una conquista social.

Sin embargo, el empeño gubernamental en hacer efectivo el proyecto quedará intacto, lo que dará como resultado la promulgación de la Ley $N^{\circ} 222$ de Consulta a los Pueblos Indígenas del TIPNIS el 10 de febrero de 2012 que constituirá el marco legal para una consulta manipulada llevada por el oficialismo entre julio y agosto del mismo año. Dicha consulta, marcada por la política de prebenda, cooptación, división y negación de las comunidades en resistencia, donde forzosamente se impuso un "sí" favorable al proyecto carretero, será instrumentalizada por el gobierno del MAS como legitimadora de la futura abrogación de la Ley 180.

Después de cinco años posteriores a la consulta de acciones gubernamentales que tenían como objetivo romper con la resistencia comunitaria en el territorio, que describiremos más adelante, el conflicto por el TIPNIS tomó nuevos aires en julio de 2017, cuando los diputados del MAS presentaron ante la Asamblea Legislativa Plurinacional el Proyecto de Ley de Protección y Desarrollo Integral y Sustentable del TIPNIS firmado por supuestos representantes de las "organizaciones indígenas"4, que viabiliza la construcción de la carretera. El 3 de agosto, bajo un fuerte resguardo policial, la Cámara de Diputados controlada por la mayoría del MAS aprueba en grande el Proyecto de Ley en medio de protestas callejeras e impugnaciones de parte de la oposición. El domingo 13 de agosto el presidente Evo Morales promulga la Ley 969 de

4 El documento cuenta con los sellos de las siguientes organizaciones y firmas de los dirigentes desconocidos por las comunidades del TIPNIS que se han declarado en resistencia, y al mismo tiempo afines al gobierno del MAS: Consejo Indígena del TIPNIS, Prov. Chapare (CONISUR), Subcentrales del TIPNIS y Sécure- TIPNIS con sus respectivos presidentes: Domingo Nogales Morales y Carlos Fabricano Moye, Coordinadora de Pueblos Indígenas del Trópico de Cochabamba (CPITCO).
Colonización y los cuerpos-territorio: protagonismo de las mujeres indígenas en el conflicto por el TIPNIS, Bolivia

Gaya Makaran 
Dossier América Latina: género y política
Protección, Desarrollo Integral y Sustentable del TIPNIS, en un acto público en el coliseo de la ciudad de Trinidad.

En nombre de la lucha contra la pobreza, el "derecho a la libre circulación" y el progreso de las comunidades indígenas, la Ley 969 abroga la Ley 180 de 2011 y de esta manera, anula la intangibilidad del TIPNIS a fin de proponer su "desarrollo integral y sustentable”. Entre sus artículos clave se encuentra el artículo 9, donde se autorizan "las actividades de articulación e integración que mejoren, establezcan o mantengan derechos de los pueblos indígenas como la libre circulación, a través de la apertura de caminos vecinales, carreteras, sistemas de navegación fluvial, aérea y otras" (Art. 9). Además, la Ley permite la explotación de recursos renovables por privados (Art. 10) y el empleo por ellos de mano de obra local (Art. 12). Esto legitima la privatización y la mercantilización de las relaciones productivas en el TIPNIS y atenta doblemente contra la economía tradicional de la zona: por una parte, destruyendo el bosque que es fuente de subsistencia y, por la otra, promoviendo la explotación laboral de la población nativa.

Frente a este atropello de los acuerdos logrados tras la VIII Marcha y la abolición "legal" de la intangibilidad garantizada por la Ley 180, lo que permitiría al Ejecutivo realizar por fin no sólo el proyecto carretero original, sino una empresa compleja de apertura y colonización del territorio, las comunidades del TIPNIS entraran en una nueva fase de protesta y resistencia, la misma que será descrita más adelante y en la cual el papel de las mujeres será el decisivo.

\section{Colonización del TIPNIS antes y durante el conflicto}

Veamos ahora con más detalle las características de la colonización que se ha llevado en el TIPNIS, tanto antes, como durante el conflicto, cuyo principal impulsor ha sido el Estado, aunque siempre en una estrecha relación con los actores privados, tanto el gran capital internacional, como los colonos particulares vinculados con el mercado y portadores de una visión empresarial de la tierra y sus recursos. Es un proceso multidimensional, puesto que implica tanto la esfera económica y política, como cultural, al modificar los modos de imaginar y relacionarse con el mundo, es decir, las subjetividades mismas de los sujetos. El proyecto carretero anteriormente descrito constituye tan sólo una avanzada de un proyecto de colonización física y epistémica más amplio, donde la razón del Estado, el control territorial y poblacional, la subsunción al capitalismo, el "desarrollo" y la productividad regresan abanderando esta nueva reencarnación de la decimonónica "lucha contra la barbarie"

Los principales agentes de esta colonización contemporánea orquestada desde el Ejecutivo son, paradójicamente, los sujetos antaño subalternos, los

5 Basta revisar algunos discursos de los diputados del MAS y del mismo gobierno, donde se pretende "salvar a los hermanos indígenas" de la miseria para que "vivan como humanos". Véase Makaran y López, 2018, pp. 275-281. 
campesinos productores de la hoja de coca (cocaleros) de origen aymara-quechua sindicalizados, que hoy en día, debido al carácter de su actividad económica y su alianza política con el gobierno ${ }^{6}$, se convierten en la fuerza de contención, disciplinamiento y represión contra los sujetos indígenas opositores. De esta manera, los colonizadores cocaleros, presentados también como “indígenas" del TIPNIS cuando hay que legitimar "orgánicamente" las iniciativas gubernamentales, aparecen como principales adversarios de los pueblos amazónicos: los yuracaré, t’simán y moxeños trinitarios, que están disputando su territorio legalmente reconocido y sus modos de vida tradicionales contra las lógicas de acumulación capitalista enmarcadas en el discurso del desarrollo, productividad y progreso, y las prácticas del clientelismo y subordinación política al Ejecutivo.

Si miramos relaciones sociales que se establecen en la zona del TIPNIS colonizada por la economía de la coca, el así llamado Polígono 7, veremos la gradual pérdida de la autonomía social que caracteriza a los habitantes originarios del territorio y su subsunción a las lógicas mercantilistas y al trabajo asalariado, frente a la destrucción de las fuentes tradicionales de subsistencia (la selva) y la jerarquización y explotación de mano de obra que conlleva el monocultivo de la coca, estrechamente vinculado con el mercado mundial de estupefacientes. Los testimonios indígenas denuncian el carácter depredador de la relación de los colonizadores con el entorno, cuyo efecto es la destrucción de fuentes de vida y sustento de las comunidades del TIPNIS:

Entraron los colonos y con dinamita comenzaron a pescar. Para nosotros quedaba casi nada. (Lucio en Layme, 23.08.2017)

Ya no hay qué pescar ni cazar en esa zona. Los colonos pescan con dinamita y, como no saben bucear, dejan algunos peces en el fondo del río, lo que contamina el río. (Zacarías en Layme, 24.08.2017)

El tema de la coca y los cocaleros, no por nada llamados por los indígenas originarios del territorio, "colonizadores", nombre con el que se denuncia su carácter expansivo y su proceder avasallador frente a la selva y sus habitantes,

6 La migración de los campesinos y exmineros aymaras y quechuas andinos al trópico, donde empiezan a dedicarse al cultivo de la hoja de coca, aunque se enraíza en la época posrevolucionaria (años 50), se intensifica en los años 70 y sobre todo 80 debido a las políticas neoliberales de despidos masivos y empobrecimiento del agro, unidas al boom de la cocaína en EE. UU. La historia de vida del mismo presidente Evo Morales, hijo de migrantes aymaras y cocalero, ilustra dicho proceso. Así, el partido del gobierno el MAS se deriva directamente de los sindicatos cocaleros del Trópico de Cochabamba que siguen siendo sus bases electorales y militantes más fieles a cambio de prebendas sectoriales. Organizados a nivel local en el CONISUR (Consejo Indígena del Sur) y a nivel regional en sindicatos que forman parte de la Federación de Trópico de Cochabamba, están reconocidos por la nueva Constitución de 2009 como "comunidades interculturales” y ocupan en el TIPNIS la zona llamada Polígono 7 (Véase Makaran y López, 2018).
Colonización y los cuerpos-territorio: protagonismo de las mujeres indígenas en el conflicto por el TIPNIS, Bolivia

Gaya Makaran 
Dossier América Latina: género y política regresa constantemente en los testimonios en tono de queja contra las acciones de los mismos y del gobierno nacional que promovió la extensión de los cultivos y la penetración cocalera en el TIPNIS, frecuentemente asociada con el fenómeno creciente del narcotráfico en la zona. Los indígenas subrayan el carácter de aliado político y agente del gobierno de las organizaciones cocaleras que le ayudan en el ejercicio de sus proyectos, como el carretero, a cambio de su permisividad en cuanto a la ocupación de territorios indígenas: "Los de CONISUR están viendo por anular la intangibilidad. Se reúnen cada 15 días viendo lo del proyecto. Y mientras van entrando, ya están allá adentro"7.

La economía de la coca penetra no sólo físicamente el territorio, sino que transforma las relaciones socioeconómicas de las comunidades indígenas afectadas por la colonización cocalera que, como se ha mencionado, empiezan a moverse alrededor de la producción y comercialización de la hoja de coca. De esta manera, los indígenas se convierten de los dueños legítimos del territorio en jornaleros que trabajan para sus nuevos patrones quechuas y aymaras, motivados por la precariedad material en la que se encuentran, entre otros, por la destrucción de su hábitat:

Nosotros nos preocupamos más por la alimentación. No nos preocupamos de tener un negocio. No decimos que la plata no sirve, nos conformamos con lo material, nuestra gran preocupación es tener algo que comer. Como ya no hay mucho para pescar ni cazar, no nos queda otra cosa que trabajar para tener un poco de dinero. (María Luisa en Layme, 20.08.2017)

De ahí, la colonización cocalera tiene como consecuencia la integración subordinada de los indígenas del TIPNIS a las dinámicas del capitalismo, al mundo donde la subsistencia sin dinero no es posible.

Otro de los aspectos de la colonización económica en el TIPNIS, vinculado, como veremos más adelante, con la dimensión política, es el acoplamiento entre la economía de la coca y los proyectos desarrollistas y extractivistas del Estado, al ser la carretera un proyecto de apertura del territorio indígena por una parte a la expansión de los sembradíos de coca, y por la otra, a posibles explotaciones petroleras ${ }^{8}$, junto con la expansión de la agroindustria y fincas ganaderas, con todo lo que esto supone para la economía tradicional amazónica. A esto hay que añadir riesgos sociales vinculados con la apertura del territorio, típicos para los enclaves extractivistas, como el tráfico de blancas, prostitución, alcoholismo, violencia y depredación de los bienes naturales, donde, dada la masculinización de las fuerzas colonizadoras, son las mujeres

7 Fabián Gil, presidente de la Subcentral del TIPNIS, Subcentral del TIPNIS, Trinidad, 11 de abril de 2017.

8 El gobierno del MAS otorgó dos concesiones para exploración y explotación petrolera en la zona del TIPNIS: la primera del 2007 a la estatal YPFB con PETROBRAS BOLIVIA S. A. y la TOTAL E\&P BOLIVIE; y la segunda del 2008 a las empresas YPFB y PETROANDINA S. A. M. (EAE, SERNAP, RUMBOL, 2011). 
y niñas las principales afectadas. En ese escenario queda claro que el TIPNIS, en la lógica gubernamental, deja de ser área protegida y territorio indígena, para convertirse en una más de las zonas a conquistar y subsumir a las lógicas "modernas". De esta manera, tanto las empresas petroleras, los latifundistas, los ganaderos, como los productores de la hoja de coca serían los agentes de la colonización territorial física y simbólica derivada del proyecto estatal de modernización capitalista.

Como vimos hasta ahora, la dimensión económica de la empresa colonizadora se entrelaza con su impacto socioambiental sobre el territorio y sus habitantes, pero también es inseparable de la dimensión política, donde la colonización se expresa en el ataque contra las formas propias y autónomas de la organización comunitaria. Fruto de un largo proceso de recuperación y articulación de formas políticas propias, los pueblos de la Amazonía boliviana se organizaron, sobre todo a partir de los años 80, en Subcentrales y Centrales ${ }^{9}$, que formaron parte de la gran Confederación de Pueblos Indígenas del Oriente Boliviano (CIDOB). La célula base de estas organizaciones es la comunidad con formas de democracia directa, con la asamblea como el órgano más importante de toma de decisiones y legitimación de las autoridades (corregidores) ${ }^{10}$, los mismos que representan a sus comunidades en asambleas regionales (cabildos) facultadas para la toma de decisiones a niveles supracomunitarios, incluida la agenda de la CIDOB. En ese contexto, en el TIPNIS la mayoría de las comunidades indígenas están organizadas en la Subcentral de Cabildos del Territorio Indígena y Parque Nacional Isiboro Sécure (Subcentral TIPNIS) fundada en 1988. La Subcentral cuenta con su sección femenina, siendo la Subcentral de las Mujeres Indígenas del TIPNIS con su presidenta y la vicepresidenta la que, además de colaborar con las acciones de la Subcentral general, presenta una agenda "de género" propia, y, últimamente, se posiciona como la principal fuerza opositora al proyecto carretero y las presiones gubernamentales.

La colonización política ${ }^{11}$ por el gobierno del MAS, causada por la necesidad de desarticular la resistencia en el TIPNIS y también las ambiciones del Ejecutivo de subordinar todo un rico y diverso campo indígena-popular a su monopolio partidario, se intensifica después de la VIII Marcha, como indican los testimonios de los y las dirigentes:

9 Por ejemplo: la Central de Pueblos Indígenas del Beni (CPIB), la Central Indígena de Pueblos Originarios de la Amazonia de Pando (CIPOAP), la Subcentral del Territorio Indígena y Parque Nacional Isiboro Sécure (TIPNIS), etc. Además, el movimiento cuenta con las organizaciones particulares de mujeres tanto a nivel de subcentrales como centrales, por ejemplo: la Central de las Mujeres Indígenas del Beni.

${ }^{10}$ Las comunidades con sus autoridades -corregidores- se organizan en una subcentral con sus propias autoridades como el presidente y el vicepresidente, los mismos que dependen de las decisiones tomadas en los cabildos de corregidores comunales. Las subcentrales, por su parte, constituyen una central, etc.

11 "Colonización política" no sólo es un término que utilizamos nosotros, sino que es como los mismos dirigentes llaman el accionar del gobierno.
Colonización y los cuerpos-territorio: protagonismo de las mujeres indígenas en el conflicto por el TIPNIS, Bolivia

Gaya Makaran 
Dossier América Latina: género y política
Cuando el pueblo se levanta a defender el territorio del TIPNIS en la octava Marcha empieza esta persecución. El gobierno ha querido someter a pueblos, especialmente a los del TIPNIS, a querer que no se defiendan, que se callen, para así entrar fácilmente al territorio y avasallar con la colonización, con el narcotráfico, con todo [...] Nosotros como los pueblos indígenas acá de Bolivia hemos sido totalmente perseguidos por el hecho de querer simplemente defender nuestros derechos, sobre todo por defender lo que es nuestra Casa Grande, que son nuestros territorios. Los pueblos, las comunidades, los dirigentes cuando se atreven decir la verdad estamos siendo atropellados. ${ }^{12}$

La persecución mencionada se expresa tanto en la infiltración, división y cooptación de las organizaciones y autoridades, como también en la criminalización, chantaje o castigo económico de las comunidades y dirigentes insumisos. No se trata aquí de la cooptación de algún que otro dirigente, sino de una acción premeditada del gobierno de destrucción de la autonomía política de los pueblos a través de intromisión, "divisionismo político" como dicen los dirigentes, subordinación o desconocimiento de las organizaciones orgánicas y sus formas tradicionales de hacer la política, lo que atenta contra la aspiración de la autodeterminación de los pueblos y promueve una toma de decisiones vertical, autoritaria y subordinada al Ejecutivo en desconocimiento del mandato de las bases:

Nuestra autodeterminación debemos hacer y aplicar basándonos en la estructura de los cabildos que están en las comunidades del TIPNIS, eso es lo que hemos hecho hasta ahora. Eso es lo que el gobierno no ha querido respetar, sigue queriendo abusar con tres pueblos que existen en el TIPNIS. [...] Antes no había intromisión del gobierno ni de las instituciones. Las instituciones eran de apoyo cuando se veía este tema de trabajo. Ahora hay esta intromisión y empieza el gobierno a partir a las organizaciones. Este es el problema que no respeta el gobierno a pesar de ser indígena. [... ¿Qué hacen los dirigentes que están actualmente, recibiendo ordenes desde arriba?, ya no son ordenes de las comunidades. ${ }^{13}$

Paralelamente a las prácticas clientelares de cooptación individual y colectiva de los que decidan alinearse al $\mathrm{MAS}^{14}$, se castiga a los opositores aplicándoles el bloqueo económico, retirando la ayuda y ahuyentando a los que

${ }_{12}$ Exdirigente de la Subcentral Secure en el Cabildo Indigenal, el 11 de abril de 2017, Trinidad.

${ }_{13}$ Expresidente de la Subcentral de TIPNIS en los años 2003-2005 en el Cabildo Indigenal, el 12 de abril de 2017, Trinidad.

${ }^{14}$ Entre los medios de persuasión se encuentra la seducción con regalos como motores, paneles solares, bombas de agua, etc., la mayoría regalada en ocasión de la "consulta"; y la difusión de la propaganda oficialista sobre los presuntos beneficios para las comunidades, como el acceso a bienes y servicios en un contexto de precariedad actual derivada de la destrucción del bosque como fuente de sustento material, provocada por la economía de la coca. 
puedan brindarla. Así, las comunidades denuncian el abandono que sufren por la falta de proyectos productivos, falta de apoyo para los dirigentes y a las organizaciones que "están con las manos atadas", al no poder solventar los gastos de transporte, organización de cabildos, comunicación o incluso su propia sobrevivencia. Todo esto con el simultáneo derroche gubernamental en las comunidades que decidan abandonar la lucha, donde se regalan bienes, inauguran escuelas, financian reuniones y premian a los dirigentes. De esta manera, los proyectos productivos y las mejoras en las comunidades son condicionados por el gobierno a cambio del apoyo que éstas puedan brindar al proyecto carretero:

Cuando estábamos solos había proyectos, se metía luz a las comunidades, ahora no hay nada. [...] Vienen los del gobierno con falsas promesas que gracias a la carretera los niños tendrán el desayuno escolar, hablan del desarrollo, gracias a la carretera. Primero nos quitan proyectos y hunden en la miseria y luego vienen a rescatarnos a cambio de la carretera. ${ }^{15}$

Lo que se destaca en los testimonios es la centralización y el monopolio estatal que imposibilita la gestión autónoma de los programas desde las comunidades y facilita el manejo arbitrario de los recursos disponibles, hecho que va en contra de las reivindicaciones históricas del movimiento indígena y contradice el anhelo de la autonomía organizativa y económica de los pueblos: "No hay nada de eso [proyectos] porque todo lo concentra el gobierno. Ya no tenemos derecho de buscar fondos para el desarrollo de las comunidades. Tiene que ser a través del Estado, está condicionado. Tienen que aceptarme el camino para que yo de plata para su desarrollo..."

Como consecuencia directa de este tipo de prácticas, hoy en día observamos una preocupante división y debilitamiento de las organizaciones indígenas del TIPNIS, en particular, y de las tierras bajas, en general. Las divisiones se evidencian de manera explícita en la convocatoria al encuentro de corregidores de las 64 comunidades del TIPNIS que se lleva en el territorio en agosto de 2017 en dos Cabildos paralelos: uno oficialista en San Pablo del Isiboro en apoyo a la Ley 969, convocado por Domingo Nogales Morales, presidente de la Subcentral del TIPNIS desconocido por las comunidades en resistencia, y el otro orgánico en su rechazo, en el Centro de Gestiones ubicado en el río Isiboro, liderado por el nuevo presidente de la Subcentral, Fabián Gil Rocha y la vicepresidenta Cecilia Moyoviri, junto con la presidenta de la Subcentral de Mujeres, Marqueza Teco Moyoviri y la vicepresidenta Adelaida Rocha. Observamos aquí la renovación de dirigencias, donde se refuerza el liderazgo de jóvenes y mujeres, un cambio importante y simbólico para esta nueva etapa de lucha por el territorio.

${ }^{15}$ Expresidente de la Subcentral de TIPNIS en los años 2003-2005 en el Cabildo Indigenal, el 12 de abril de 2017, Trinidad.
Colonización y los cuerpos-territorio: protagonismo de las mujeres indígenas en el conflicto por el TIPNIS, Bolivia

Gaya Makaran 
Dossier América Latina: género y política
De manera paralela a la división de las dirigencias del TIPNIS, se lleva la cooptación y la subordinación a las políticas oficialistas de la organización matriz indígena de las tierras bajas, la CIDOB. Así, en la Gran Asamblea Nacional de los Pueblos Indígenas GANPI convocada el 23 de agosto de 2017, resultarán ganadores los dirigentes afines al gobierno del $\mathrm{MAS}^{16}$, mientras la única candidata crítica a las políticas del Ejecutivo, la moxeña ignaciana Berta Bejarano, quedará derrotada en la votación. Por estas razones tanto la Subcentral del TIPNIS orgánica y la Subcentral de Mujeres del TIPNIS, como también la Central de Pueblos Étnicos Mojeños del Beni (CPEMB), cuya presidente fue en su tiempo Bertha Bejarano, desconocieron la nueva dirigencia de la CIDOB. Como asegura Maribel Daza, dirigente de la CPEMB: “...hemos sido testigos del manoseo político de la Asamblea, por ello, orgánicamente no nos representa el señor Pedro Vare. Nosotros somos orgánicos y obedecemos lo que nuestras bases nos manden..." (CEJIS, 2017). De nuevo son los liderazgos femeninos los que toman un renovado protagonismo en las organizaciones en resistencia, al marcar un fuerte e intransigente antagonismo con el gobierno y sus políticas.

Frente a la existencia de estos sujetos políticos "rebeldes", las autoridades gubernamentales aplican la táctica de negación, silenciamiento y de ninguneo, al reconocer como interlocutores válidos sólo a los dirigentes varones subordinados al Ejecutivo. De esta manera, este no reconocimiento y anulación como actores políticos autónomos de los y las opositores conlleva también altos grados del sexismo, al ser las mujeres dirigentes las más despreciadas, subestimadas políticamente y ridiculizadas, convertidas más bien en objetos sin voluntad propia y cuerpos manipulables, destinados a conquistar por los machos, depositarios "naturales" del poder. Este tipo de posturas, manifestadas sin disimulo por el gobierno y sus aliados, se desprenden de una mirada profundamente patriarcal sobre el poder y su ejercicio, enmarcada en el ethos colonizador, como lo demuestran las palabras del presidente Morales, dirigidas a los "compañeros cocaleros" en medio del conflicto por el TIPNIS: "Si yo tuviera tiempo iría a enamorar a las compañeras yuracarés y convencerlas de que no se opongan a la ruta sobre el TIPNIS, así que jóvenes tienen instrucciones del presidente de conquistar a las compañeras yuracarés trinitarias para que no se opongan a la construcción del camino" (Evo Morales citado en Infobae, 2011). La recomendación del presidente, además de misógina y machista, expresa justamente aquel ethos colonizador que se niega a desaparecer: la mujer como territorio a conquistar y dominar, el territorio que puede ser conquistado y dominado a través de la violencia ejercida contra las mujeres.

${ }^{16}$ Como presidente de la CIDOB es elegido Pedro Vare, moxeño-trinitario, presidente de la Central de Pueblos Indígenas del Beni, en su tiempo participante de la VIII Marcha y hoy en día dirigente afín al MAS y partidario declarado de la carretera por el TIPNIS. Como vicepresidente se elige al representante de la Asamblea del Pueblo Guaraní (APG), Efraín Balderas, igualmente simpatizante del oficialismo. 
De ahí, la colonización actual, aunque frecuentemente se viste de formas más sutiles que las de antaño, sigue siendo sumamente violenta. Esta violencia puede ser tanto simbólica y estructural, como física y directa, como en Chaparina, cuando las fuerzas del orden atacaron a los y las indígenas defensores del territorio. En los testimonios se subraya el carácter sorpresivo de la represión, ante la gente desmovilizada que retomaba fuerzas en el campamento para el siguiente tramo del camino, contra ancianos, mujeres y niños que de repente se vieron rodeados por la policía. En los relatos se reviven las imágenes de la persecución de dirigentes, de mujeres "chorreando sangre", de niños abandonados en aquel caos, llorando por sus madres, el campamento destrozado y los policías llevándose a las personas en dirección desconocida:

No esperábamos nada, nadie sabía, los niños jugando por allí, nosotras cocinando, las otras lavando y de repente... No sabíamos ni de nuestros hijos, algunos chiquititos, algunos recién dados a luz. A algunos viejitos se los llevaban pal monte, para subirlos a unas flotas para llegar a no sé dónde. $Y$ nos quemaban nuestras carpas, se robaban lo que ellos querían, todo lo quemaban. Que cosa [...]. Dos días estuvieron desaparecidas las mamás, no sabían dónde estaban los niños. [..] Peor que animales nos trataron, gasificados, maltratados. ${ }^{17}$

Ante la violencia, las mujeres, indignadas por el maltrato que sufrieron ellas y sus hijos/as, toman la decisión fuerte de seguir marchando. Ante la pregunta por el miedo que podrían haber sentido en aquel momento, contestan en unísono: "Nosotras no tenemos miedo. Es como dice el dicho cuando el marido te pega y te pega, una no tiene miedo en la vida." ${ }^{18}$ La metáfora de la mujer maltratada por su marido aparece de manera recurrente en estos relatos femeninos, al ser el Estado el macho maltratador, de cuyos golpes, con el tiempo, se pierde el miedo sustituido por el coraje.

Podemos destacar aquí el carácter colonialista y patriarcal de la represión, donde son los cuerpos indígenas insumisos, y particularmente de las mujeres, los que constituyen para el poder el objetivo a castigar, reducir y subyugar a fuerza de golpes. La manera de que se rompe el lazo de las madres con sus hijos, la inseguridad y el terror que sienten las mujeres por estar separadas de su prole y la situación de su vulnerabilidad, la irrupción de la policía en el espacio de lo "femenino" cuando las mujeres se dedicaban a los cuidados indispensables para la sustentación vital de la lucha, todos estos elementos indican en una acción premeditada de violencia como terror, dirigida contra

17 Palabras de una de las dirigentas presentes en la reunión en el Cabildo Indigenal, el 11 de abril de 2017.

${ }^{18}$ Una de las dirigentas yuracaré de las comunidades del TIPNIS en el Cabildo Indigenal, el 11 de abril de 2017, Trinidad.
Colonización y los cuerpos-territorio: protagonismo de las mujeres indígenas en el conflicto por el TIPNIS, Bolivia

Gaya Makaran 
Dossier América Latina: género y política la vida comunitaria misma, donde el papel de las mujeres y sus labores es fundamental para mantener la lucha política, y el ataque contra ellas se entiende como ataque contra los órganos vitales del movimiento de resistencia.

\section{Defensa del territorio y el latido de la resistencia}

A partir de la promulgación de la Ley 969 en agosto de 2017 se abre un nuevo periodo de la lucha comunitaria, marcado por la división y la vulnerabilidad de las organizaciones y los liderazgos, donde al mismo tiempo el territorio y la comunidad se convierten en la base de la resistencia. En los siguientes apartados describiremos las acciones indígenas que lograrán abrir una vez más el conflicto por el TIPNIS, en el que se evidenciará el carácter colonial y colonizador del Estado boliviano bajo los gobiernos del MAS.

Una de las estrategias del movimiento indígena en defensa del TIPNIS son los pronunciamientos públicos dirigidos a la sociedad nacional boliviana donde se denuncia, en busca de la solidaridad, los atropellos del gobierno. Así, en marzo de 2017, cuatro meses antes de la promulgación de la Ley 969, la Subcentral de Mujeres difundió un documento ${ }^{19}$, donde se denunciaba "la avanzada amenaza del Gobierno central del Estado Plurinacional de Bolivia en la construcción de la carretera por el corazón del TIPNIS y la abrogación de la ley 180." El pronunciamiento reiteraba, una vez más, el rechazo de las mujeres indígenas y las comunidades a la construcción de la carretera y la violación sistemática de los derechos colectivos y condenaba "el acto mentiroso, prebendas, la colonización permanente y despojo" contra los pueblos mojeño trinitario, yuracaré y t'simán del territorio del TIPNIS. Frente a eso, anunciaban "defender hasta la muerte nuestro territorio" puesto que "derechos colectivos y territorio no se venden ni se negocian, se respetan", y se declaraban "en estado de emergencia y movilización continua por el atropello permanente del gobierno, la colonización política partidaria, la cooptación y la violación de la CPE y normas internacionales".

Es importante destacar el papel de la organización femenina de la Subcentral del TIPNIS que, frente a la cooptación por el oficialismo de los líderes masculinos como el presidente de la Subcentral Domingo, se posiciona como la principal coordinadora de la resistencia y los liderazgos de mujeres como Marqueza Teco y Adelaida Rocha, y más recientemente Cecilia Moyoviri, se convierten en símbolos de beligerancia y fuerza en un contexto de desesperanza. La resistencia y la defensa de sus derechos, como dice Rocha, se lleva bajo el signo de su doble condición de mujer y de indígena:

19 El documento de la Subcentral de las Mujeres del TIPNIS, del 4 de marzo de 2017, firmado por la presidenta Marqueza Teco, la vicepresidenta Adelaida Rocha y representantes de las comunidades. 
Soy una mujer yuracaré, nos hemos defendido hasta donde hemos podido. [...] Jamás voy a renunciar a mis derechos como mujer, como indígena, como yuracaré. Lo que siento en mi corazón se los estoy diciendo. ${ }^{20}$

Son también las mujeres del TIPNIS las que responden a las descalificaciones vertidas desde el Ejecutivo contra la legitimidad de su lucha, como cuando el presidente Morales en ocasión de entrega de equipamiento y maquinaria a los colonizadores del CONISUR (Ministerio de Comunicación, 2017), acusó a los opositores de la carretera de recibir el financiamiento desde el extranjero. De esta manera, la Subcentral de Mujeres enfrentó al mandatario en el documento público Respuesta de las mujeres indígenas del TIPNIS frente a las acusaciones que hace el presidente Evo Morales Ayma a las ONG (Página Siete, 5.9.2017), donde con unas palabras crudas y directas denunciaron la falsedad del doble discurso presidencial aparentemente proindígena, pero que en realidad promueve a los grupos de poder y agentes que destruyen el TIPNIS, interesados por la mercantilización del territorio. Las mujeres denunciaron también las prácticas prebéndales y clientelistas del gobierno a lo que opusieron su defensa firme e incorruptible de su "Casa Grande" y retaron al presidente Morales:

Señor Presidente, quiere investigar a las ONG, inicie su investigación. Nosotras seguiremos defendiendo nuestro patrimonio y nuestra Casa Grande, porque el que apoya no es ninguna ONG, el que apoya económicamente y materialmente es el propio pueblo boliviano, lo hace porque está consciente que debe proteger su patrimonio para nuestros hijos y las futuras generaciones. [...] Nosotras, las mujeres del TIPNIS, defenderemos con nuestras vidas nuestro hábitat y si quiere que corra sangre por los ríos del TIPNIS correrá. Le decimos muy claro que esa carretera no pasará por el TIPNIS. (subrayado nuestro)

Es destacable la determinación de las mujeres del TIPNIS que deciden defender su territorio hasta las últimas consecuencias, incluido el sacrificio de sus vidas, si el gobierno no desista de su ambición de colonizarlo.

Estas declaraciones de las defensoras del TIPNIS no parecen exageradas, de hecho, en su lucha corren riesgo de ser víctimas de violencia física, como en el caso de la represión en Chaparina o, más recientemente, durante la militarización que acompañó los cabildos paralelos en agosto de 2017, cuando resultó golpeada la presidenta de la Subcentral de Mujeres, Doña Marqueza ${ }^{21}$ (Véase

${ }^{20}$ Vicepresidenta de la Subcentral de Mujeres del TIPNIS, Adelaida Rocha en el Cabildo Indigenal, el 12 de abril de 2017, Trinidad.

${ }^{21}$ La militarización consistió en la presencia, por primera vez en la historia del territorio, de la naval boliviana en los ríos del TIPNIS enviados para proteger a los participantes del Cabildo oficialista. Los y las habitantes en resistencia se opusieron al paso de los militares, poniendo alambres en los ríos, lo que derivó en un forcejeo donde resultaron golpeados varios indígenas.
Colonización y los cuerpos-territorio: protagonismo de las mujeres indígenas en el conflicto por el TIPNIS, Bolivia

Gaya Makaran 
Dossier América Latina: género y política
Página Siete, 29.08.2017). La dirigente, conmovida por esta violencia, hace un llamado a los comunarios que acompañan a la naval camino al cabildo oficialista: “¿Qué hemos hecho para que nos traicionen?, ¿Dónde van a ir a vivir sus hijos?” (Chaski Clandestino, 6.09.2017). La voz indignada de Doña Marqueza expresa la preocupación principal que mueve a las demás mujeres defensoras del TIPNIS, el futuro de sus hijos.

De ahí, la cuestión del territorio y su vínculo con la reproducción de la vida comunitaria y la sucesión generacional es el tema clave para entender las causas de la resistencia y su latido propio, según un sentir colectivo que subjetiva la lucha y la dota de sentido. Con coraje y orgullo los y las defensores del TIPNIS aseguran de su decisión firme de luchar, si fuera necesario "hasta con arcos y flechas" 22 , y explican por qué no podría ser de otra manera: "Es nuestra Casa Grande, tenemos que defenderla"; "es donde vivieron, procrearon y murieron nuestros antepasados"; "es el futuro de nuestros hijos"; "el bosque nos da la vida"23. Para los y las indígenas del TIPNIS, la defensa del territorio significa la defensa de su propio existir como pueblos, puesto que éste significa mucho más que un simple espacio físico, al constituir la razón de ser de las comunidades: define y le da sentido a lo que son como pueblos, le da una identidad propia derivada de los huesos de sus abuelos. Para ellos, la selva es algo que precede y que conduce, es “permanente y eterna”, lo que garantiza la reproducción generacional de su pueblo, lo que lo define como tal, lo que lo enraíza y lo que le asegura el futuro. La lucha actual por protegerla es vista como una misión sagrada, puesto que, como explica Marqueza Teco:

El territorio, nuestra Casa Grande que es donde habitamos nosotros. Desde siempre lo hemos habitado, nuestros ancestros, nuestros antepasados, por eso que nosotros la protegemos. [...] No queremos destrucción, no queremos sufrir en el TIPNIS porque es nuestra Casa Grande, allí habitamos, que Dios nos la dio para que la protejamos, lo cuidemos, es el pulmón de Bolivia $y$ de todo el mundo. También como las mujeres nosotras defendemos nuestra tierra, defendemos los derechos, defendemos lo que en la Constitución dice. ${ }^{24}$

La presencia de la naval marca un hito y constituye un claro despliegue de la ambición monopólica del Estado de desconocer a los legítimos dueños del territorio. Esta imposición simbólica y física del monopolio de la violencia estatal que acompaña los esfuerzos por el control territorial único, según la lógica de conquista y colonización, característica inherente a las relaciones históricas que se establecen entre el Estado boliviano y las tierras bajas, tenía como objetivo ejercer presión sobre los comunarios y disuadirlos de la lucha contra el proyecto gubernamental.

${ }_{22}$ Véanse las palabras del presidente de la Central de Pueblos Étnicos Mojeños del Beni (CPEM-B), Adhemar Mole: "Vamos a defender el territorio hasta con arcos y flechas", en Layme, 11.08.2017.

${ }^{23}$ Voces de las y los dirigentes escuchadas en el Cabildo Indigenal, el 11 y 12 de abril de 2017, Trinidad.

${ }^{24}$ Marqueza Teco, presidenta de la Subcentral de Mujeres del TIPNIS, en el Cabildo Indigenal, 12 de abril de 2017, Trinidad [subrayado nuestro]. 
De esta manera, el seguir resistiendo, además de ser la manera de honrar la memoria de los abuelos que sacrificaron sus vidas en la defensa del territorio, es una contienda por la sobrevivencia misma de los pueblos del TIPNIS.

Y son las mujeres indígenas las que siguen luchando por la tierra, el territorio, sus derechos colectivos, entre ellos la autodeterminación de sus pueblos, subrayando ellas mismas con orgullo su empeño e intransigencia, reconocidas por sus compañeros que admiten: cuando los varones desisten, se rinden o corrompen, allá están las mujeres para seguir con la lucha. ¿Cómo se explica este fenómeno? Ellas mismas lo explican, evocando su papel que desempeñan como mujeres en sus comunidades: son las encargadas de reproducir la vida, de cuidar y alimentar, de asegurar el agua fresca, la leña y los alimentos que les da la naturaleza. Ellas saben que la destrucción del bosque supondrá un peligro directo para el sustento de sus hogares y para el futuro de sus hijos:

No nos vamos a cansar de hablar en defensa del TIPNIS, sobre todo el derecho de las mujeres y también de los niños, porque si se destruye el TIPNIS no sólo va a afectar al ser humano sino también a todos los animalitos, a todo lo que existe en el bosque. ${ }^{25}$

De ahí, no hay que olvidar que la resistencia de las mujeres del TIPNIS no se limita a la lucha estrictamente política, aunque éste fue el enfoque de nuestro artículo, y que se lleva en diferentes frentes, entre ellos en las áreas de salud, la educación, los proyectos productivos y de cuidado medioambiental. Es así, porque la colonización y el patriarcado son multidimensionales y pretenden penetrar todas las esferas de la vida y en todas ellas las mujeres se empeñan por conservar su autonomía social, pero sobre todo seguir reproduciendo la vida de sus comunidades, buscando mejorar las condiciones materiales y su propia posición desde un cuestionamiento cada vez más visible de las relaciones de poder externas e internas.

El protagonismo político de las mujeres indígenas en defensa del TIPNIS está marcado también por una nueva conciencia de luchar y representar a la causa femenina, aparte de la defensa territorial, por lo cual en sus discursos son frecuentes alusiones a otras mujeres luchadoras, a ser "sólo una de muchas" y de compartir las mismas experiencias con las demás compañeras. De esta manera los cuerpos individuales de las mujeres se acuerpan en un solo cuerpo en resistencia, un cuerpo-territorio que tal como puede ser lastimado y violentado por el proyecto colonizador, igual puede hacerle frente y combatirlo, sacando fuerza de una experiencia de vida compartida.

25 Adelaida Rocha, vicepresidenta de la Subcentral de Mujeres del TIPNIS, Subcentral del TIPNIS, el 11 de abril de 2017, Trinidad.
Colonización y los cuerpos-territorio: protagonismo de las mujeres indígenas en el conflicto por el TIPNIS, Bolivia

Gaya Makaran 
Dossier América Latina: género y política

\section{Reflexiones finales}

Como hemos podido ver a lo largo del texto, el proyecto gubernamental del MAS, evidenciado en el conflicto por el TIPNIS, responde a un nacionalismo monopolizador en su sentido político, basado en el extractivismo de vinculación subordinada al capital global y a las visiones "modernas" del progreso y desarrollo. En nombre de estos últimos se aplica en el TIPNIS la política de destrucción de las formas de vida comunitarias, imponiendo una territorialidad y un espacio-tiempo de la modernidad capitalista estadocentrada, arrasando con las otras formas de pensar y producirse en el territorio, más allá de la lógica de la utilidad mercantil. Este proceso de colonización económica, política y cultural se lleva de manera violenta, apoyándose el gobierno en un discurso y un imaginario que se inscriben en una larga tradición del ethos del colonizador aplicado contra los pueblos indígenas de las tierras bajas considerados "incivilizados" e "improductivos".

Frente a estas prácticas fuertemente marcadas por el patriarcado, surge el protagonismo femenino y se lleva en el contexto de la oposición a la subordinación política de las organizaciones y de los sindicatos al poder ejecutivo, donde los dirigentes, proclives al clientelismo y cooptación, frecuentemente sucumben ante presiones gubernamentales. Son entonces las mujeres indígenas las que retoman las dirigencias, rebelándose contra la corrupción política de algunos de sus compañeros. Así, hoy en día son las lideresas indígenas y campesinas, las que se resisten a aceptar los modelos de desarrollo impuestos, defienden la autonomía y el territorio como garantes de sobrevivencia de los pueblos indígenas, oponiéndose a la colonización multidimensional perpetuada por el Estado y el capital. Cometen de esta manera una doble transgresión: como indígenas contra el racismo y explotación, y como mujeres, contra el domino patriarcal, expresada por Rita Segato bajo el concepto de la "colonialidad de género" (Segato, 2015, p. 321).

Aparece de esta manera la figura de la mujer míticamente vinculada con la Tierra, la que da y reproduce la vida, pero también la que personifica con su cuerpo el territorio mismo. Esto queda más que explícito en la lógica de la conquista, tanto con la imagen recurrente de la selva como una virgen indomable que tiene que ser dominada con violencia por el conquistador masculino, como en las prácticas concretas de la ocupación territorial a través de la sumisión de las mujeres, tomando sus cuerpos en posesión. Aunque pareciera que estas lógicas son propias de las épocas lejanas de las primeras horas de la Colonia, en realidad, como hemos visto, se siguen reproduciendo en nuestros días, A esta violencia, tanto directa como estructural derivada del capitalismo, en sí patriarcal, que históricamente ha apuntado en la subordinación de la mujer a través del despojo de los medios de reproducción de vida, de sus conocimientos y del control sobre su cuerpo, las mujeres del TIPNIS responden con resistencia, decididas a defender su dignidad, junto con el territorio donde sustentan y reproducen la vida. 


\section{Referencias bibliográficas}

Belausteguigoitia Ruis, M. y Saldaña-Portillo, M. J. (2015). Des/posesión: genero, territorio y luchas por la autodeterminación. México: PUEG, UNAM.

CEJIS (25.08.2017). La GANPI y el maripeo mojeño. Recuperado 25.08.2017 de http:// cejis.org/la-ganpi-y-el-maripeo-mojeno/

Chaski Clandestino (6.09.2017). Militarización, hostigamiento y la obstinada lucha por el territorio y la dignidad en el Tipnis. Parte 1 y 2. Recuperado 6.09.2017 de https:// chaskiclandestino.wordpress.com/2017/09/06/militarizacion-hostigamiento-y-laobstinada-lucha-por-el-territorio-y-la-dignidad-en-el-tipnis/\#more-1928

Díaz-Polanco, H. (2006). Elogio de la diversidad. Globalización, multiculturalismo y etnofagia. México: Siglo XXI Editores.

EAE, SERNAP, RUMBOL, (2011). Evaluación Ambiental Estratégica del TIPNIS. Recuperado de: www.cambioclimatico.org.bo/derechosmt/092011/280911_1.pdf

Federici, S. (2010). Calibán y la bruja. Mujeres, cuerpo y acumulación originaria. Madrid: Traficantes de Sueños.

Gargallo Celentani, F. (2014). Feminismos desde Abya Yala. Ideas y proposiciones de las mujeres de 607 pueblos en Nuestra América. México: Editorial Corte y Confección.

Gómez Grijalva, D. (2013). Mi cuerpo un territorio político. Voces Descolonizadoras, Cuaderno 1. Brecha Lésbica.

Infobae (4.08.2011). Critican a Morales por una frase machista. Recuperado 30.11.2017 de https://www.infobae.com/2011/08/04/1030718-critican-morales-una-frase-machista/

Layme, B. (11.08.2017). Indígenas articulan la defensa del TIPNIS y otros alistan el festejo. Página Siete, La Paz. Recuperado 11.08.2017 de http://paginasiete.bo/nacional/2017/8/11/ indigenas-articulan-defensa-tipnis-otros-alistan-festejo-147942.html

Layme, B. (20.08.2017). Los indígenas del TIPNIS son 'peones' en su propia tierra. Página Siete. Recuperado 20.08.2017 de http://www.paginasiete.bo/nacional/2017/8/20/indigenastipnis-peones-propia-tierra-148990.html

Layme, B. (23.08.2017). Entre la selva y el río, la vida en el TIPNIS fluye de manera simple. Página Siete. Recuperado 23.08.2017 de http://www.paginasiete.bo/nacional/2017/8/23/ entre-selva-rio-vida-tipnis-fluye-manera-simple-149347.html

Layme, B. (24.08.2017). Los indígenas que se ilusionan con la carretera rechazan a los colonos. Página Siete. Recuperado 24.08.2017 de http://www.paginasiete.bo/nacional/2017/8/24/ indigenas-ilusionan-carretera-rechazan-colonos-149460.html

Makaran, G. y López, P. (2018). Recolonización en Bolivia. Neonacionalismo extractivista y resistencia comunitaria. México: Bajo Tierra, CIALC, UNAM.

Mies, M. y Shiva, V. (1997). Ecofeminismo. Teoría, crítica y perspectivas. Barcelona: Editorial Icaria.

Millán, M. (coord.), (2014). Más allá del feminismo: caminos para andar. México: Red de Feminismos Descoloniales.

Ministerio de Comunicación (2017). El presidente Morales entrega equipos y maquinaria a comunidades del Conisur -TIPNIS, 2.09.2017. Recuperado 2.09.2017 de http://www. comunicacion.gob.bo/?q=20170902/24104 [consultado:].
Colonización y los cuerpos-territorio: protagonismo de las mujeres indígenas en el conflicto por el TIPNIS, Bolivia

Gaya Makaran 
Dossier América Latina: género y política
Página Siete (29.08.2017). Militares y un grupo indígena se enfrentaron en un río del TIPNIS. Recuperado 29.08.2017 de http://www.paginasiete.bo/nacional/2017/8/29/ militares-grupo-indigena-enfrentaron-tipnis-150145.html

Página Siete (5.09.2017). Mujeres del TIPNIS a Evo: "Quien nos apoya es el pueblo". Recuperado 5.09.2017 de http://www.paginasiete.bo/nacional/2017/9/5/mujeres-tipnisevo-quien-apoya-pueblo-150910.html

Parejas Moreno, A. (2008). El Señor de Eldorado. Santa Cruz de la Sierra: Puraletra, La Hoguera.

Santa Cruz, L. (2008). El cuerpo como territorio, el territorio como cuerpo. Revista Flor del Guanto, no. 2. Quito: Casa Feminista de Rosa.

Segato, R. L. (2015). Género y colonialidad: del patriarcado de bajo impacto al patriarcado moderno. En M. Belausteguigoitia Ruis, y M. J. Saldaña-Portillo, Des/posesión: genero, territorio y luchas por la autodeterminación. México: PUEG, UNAM, pp. 321-350.

Shiva, V. (1995). Abrazar la vida: mujer, ecología y desarrollo; La praxis del ecofeminismo: biotecnología, consumo y reproducción. Madrid: Editorial Horas y Horas. 